\title{
Removing MBD Using Fe203 NPs Modified by FeCl3 (0.1 M and 0.3 mM) With Myrtle Leaf Extract As Environmental Application
}

\section{Wisam Aziz}

Mustansiriyah University

Muslim Abid

Mustansiriyah University

Aya Jumaa ( $\nabla$ ayajumaa48@gmail.com )

Mustansiriyah University

\section{Research Article}

Keywords: Biosynthesis, Fe203, photo catalyst, methylene blue dye

Posted Date: November 11th, 2021

DOI: https://doi.org/10.21203/rs.3.rs-1054607/v1

License: (c) (i) This work is licensed under a Creative Commons Attribution 4.0 International License.

Read Full License 


\section{Abstract}

In this study, iron oxide nanoparticles were synthesized using $\mathrm{FeCl}_{3}(0.1 \mathrm{M}$ and $0.3 \mathrm{M})$ with myrtle leaf extract for of methylene blue dye (MBD) degradation under visible light irradiation (100-watt halogen lamp) as environmental application. X-ray diffraction analysis showed the polycrystalline structure of $\mathrm{Fe}_{2} \mathrm{O}_{3}$ material with miller indices confirmed the presence of iron oxide with average crystalline sizes (15.59-16.8 nm) synthesized by $(0.1 \mathrm{M}-0.3 \mathrm{mM})$ concentrations of $\mathrm{FeCl}_{3}$. Field emission-scanning electron microscopy revealed rods-like and spherical shapes of $\mathrm{Fe}_{2} \mathrm{O}_{3}$ nanoparticles, with an average particle size of 25 to $67 \mathrm{~nm}$, covered the whole top surface of structure. Moreover, the change of the color of the iron oxide NPs from brown to dark brown enhances the transformation of the properties of the material obtained by adding the biomass which gives the absorbance peaks around $265-350 \mathrm{~nm}$ and energy band gaps ( 3 and $3.7 \mathrm{eV}$ ) using UV/VIS spectrometer. The methylene blue degradation efficiencies of $\mathrm{Fe}_{2} \mathrm{O}_{3} \mathrm{NPs}$ prepared by plant extract and $\mathrm{FeCl}_{3}$ with concentrations $(0.1 \mathrm{M}$ and $0.3 \mathrm{mM})$ were $86.3 \%$ after 150 min and $90 \%$ after 120 min respectively.

\section{Introduction}

The methods of nanomaterial's synthesis are usually classified to either physical or chemical methods, the examples of physical methods are physical vapor deposition (PVD) [1], pulsed laser Ablation [1 and 2], microwave-assisted synthesis [4 and 5], high energy ball milling [6], lithography[7-9], plasma [10 and 11] and spark discharge [12 and 13]. These methods have some limitations, because require equipment of high cost with high energy [14].

Similar problems are likely to be faced including production of toxic chemicals and using expensive substances in chemical synthesis methods such as sol-gel process [15 and 16] co-precipitation [17],and chemical vapor deposition [18 and 19]. Therefore, some researchers tend to use environmentally friendly and cheaper method in addition to avoiding toxic chemicals and high energy, so as to save energy [20 and 23]. This method is called green synthesis achieved using the biological components molecules including microorganisms, biomolecules, and plants extracts that can reduce nanoparticles and preserve their shape and size. The biosynthesis method follows the bottom-up approach and involves either reduction or oxidation reactions [24 and 26].

Water purification from textile dyes is one of the important things to preserve our environment in general and this done by various ways like, adsorption[27], ion-exchange[28], UV treatment[29], ozonation [30], Gamma irradiation [31] and biological method [32]. These days the photo degradation method is considered as highly efficient and easy to apply [33-36]. But it needs a photo catalyst having high surface area, stability, photocatalytic activity and biocompatibility. Photocatalyst surface modification increases the charge separation and lifetime of carriers for reduction of the recombination process to improve the degradation efficiency. 
The aim of this study is a synthesize of iron oxide NPs with different concentration of $\mathrm{FeCl}_{3}$ using plant leaf extract (myrtle) as reducing/stabilizing agent and studying its photocatalytic efficiency of methylene blue dye degradation.

\section{Experimental Part}

\section{1 preparation plant leaves extract}

Myrtle plant leaves were chosen to synthesis and improved iron oxide NPs properties. These leaves were chopped, dried for few days and then grinding them into powder. The extract was prepared by adding an amount $(1 \mathrm{gm})$ of dried leaves to $50 \mathrm{ml}$ of distilled water and stirred it by magnetic stirrer (at $500 \mathrm{rpm}$ and $80^{\circ} \mathrm{C}$ ) for 90 min then the solution was filtered and cooled.

\subsection{Preparation iron oxide nanoparticles}

Two concentrations of $\mathrm{FeCl}_{3}(0.1 \mathrm{M}$ and $0.3 \mathrm{mM})$ put in $100 \mathrm{ml}$ of distilled water to prepare iron oxide nanoparticles and mixed with myrtle plant extract. The formation of nanoparticles was confirmed by changing the color of precursor solution to dark brown. After that the solution was centrifuged at 3500 $\mathrm{rpm}$ for $10 \mathrm{~min}$. Optical properties of solution were obtained by UV-Vis spectroscopy and finally the solution was dried in oven at $300^{\circ} \mathrm{C}$ for 2 hours to produce the nanoparticles powder and become ready to characterize by X-Ray diffraction and FE-SEM. Figure (1) reveal the flowchart of $\mathrm{Fe}_{2} \mathrm{O}_{3} \mathrm{NPs}$ formation mixing with myrtle leaves plant.

\section{Characterization}

XRD measurements have been examined with Cu-Ka radiation $(\lambda=1.54065 \AA)$ with $2 \theta$ that ranged from $20^{\circ}$ to $90^{\circ}$, and the crystallite size was calculated using the Debye-Scherer equation[37]:

$D=\frac{\mathrm{K} \lambda}{\beta \operatorname{Cos} \theta}$

Where $\mathrm{K}$ is constant value (0.9) called shape factor, $\lambda$ is the wavelength of $\mathrm{X}$-ray $\left(0.1541 \mathrm{~A}^{0}\right), \beta$ is FWHM (full width half maximum intensity of diffraction peak), and $\theta$ is the angle of diffraction.

Field emission scanning electronic microscopy (FE-SEM) used to examine the morphology, microscopic structural characteristics, and size distribution of the synthesized NPs at different (KX) magnifications. Optical absorption spectrum had been recorded using UV-Vis spectrometer within a wavelength range of 200-900 $\mathrm{nm}$ at ambient temperature.

\section{Results And Discussion}

\subsection{XRD spectrum}


Figure (2A) reveals XRD pattern of synthesized iron oxide nanoparticles using $0.1 \mathrm{M}$ of $\mathrm{FeCl} 3$ which consists of the strongest peaks and their miller indices are : (012), (024), (116) (211), (400) (104) and (541) (compared and analyzed with JCPDS file no: 1309-37-1). (104) (JCPDS file no: 01-072-6228), peaks at (111) and (200) (JCPDS file no: 01-079-1969) and peak at (440) with JCPDS file no: 00-0220346. The average crystalline size of strongest 3 peaks is $16.8 \mathrm{~nm}$. Figure (2B) explain the miller indices peaks of iron oxide NPs synthesized by concentration of $0.3 \mathrm{mM}$ of FeCl3 corresponding to (031), (104), (533) and (206) (JCPDS file no: 1309-37-1), (220) (JCPDS file no:00-026-1136), (006) (JCPDS file no:01072-6228), (131)( JCPDS file no:00-056-1302), indicate to the formation of iron oxide nanoparticles with average crystalline size $15.59 \mathrm{~nm}$.

4.2 Field emission scanning electronic microscopy

The morphology of iron oxide NPs has been monitored using FE-SEM analysis. Figure (3A) shows rodslike shape of iron oxide NPs prepared by concentration $0.1 \mathrm{M}$ of FeCl3. The particle size ranges from 25$50 \mathrm{~nm}$. In Figure (3B) the concentration is $0.3 \mathrm{M}$ of FeCl3 such the particles are spherical shape with size ranges from $42-67 \mathrm{~nm}$.

\subsection{Absorbance spectrum}

From figure (4A) it can be observe the absorbance spectrum value of prepared iron oxide NPs with myrtle leave extract and concentration $0.1 \mathrm{M}$ of $\mathrm{FeCl} 3$ at wavelength $236 \mathrm{~nm}$ and the absorbance spectrum value of Fe2O3 NPs prepared with concentration $0.3 \mathrm{mM}$ of $\mathrm{FeCl} 3$ appears in $275 \mathrm{~nm}$ as shown in figure (4B).

\subsection{Energy band gap}

The energy band gap were estimated by plotting of (ahu) 2 versus photon energy (hu). The extrapolation of the straight line to (ahu) 2 gives the value of the energy gap about $3.00 \mathrm{eV}$ for iron oxide NPs prepared with concentration $0.1 \mathrm{M}$ of $\mathrm{FeCl} 3$ as shown in figure (5A), while the energy band gap value increase to 3.7 $\mathrm{eV}$ when prepared the nanoparticles with concentration $0.3 \mathrm{mM}$ of $\mathrm{FeCl} 3$ as illustrate in figure (5B).

\subsection{Degradation of methylene blue dye (MBD)}

To study the efficiency of synthesized nanoparticles as a photo catalyst, methylene blue dye prepared in concentration of 0.001 of dye powder in $750 \mathrm{ml}$ of distilled water and adding $0.07 \mathrm{gm}$ of iron oxide NPs to $80 \mathrm{ml}$ of dye. To measure the degradation of MBD, the sample has been kept in dark place for 1 hour with stirring on magnetic stirrer after that keeping it again under irradiation of (100-watt halogen lamp) and measuring the optical absorption of the dye to confirm the degradation.

For nanoparticles prepared with concentration $0.1 \mathrm{M}$ of FeCL3, it has been required 30 min for degradation as shown in figure (6A) with addition of $\mathrm{NaOH}$ until the $\mathrm{pH}$ of solution reached to 10 . After irradiation, $10 \mathrm{ml}$ of suspension was taken every $30 \mathrm{~min}$ and centrifuged at $2500 \mathrm{rpm}$ for $15 \mathrm{~min}$. as observe in figure (6B) the degradation is start after 20 min of irradiation without adding $\mathrm{NaOH}$. 
The absorbance of the supernatant was measured by UV/Vis spectrometer by monitoring the absorption maximum at $\lambda=660 \mathrm{~nm}$ to obtain degradation efficiency with time of irradiation from 30 min to $150 \mathrm{~min}$. Figure (7) illustrates the degradation of MB dye is reached to 0.2 after 150 min of irradiation and absorption maximum at $\lambda=660$.

The degradation percentage was determined using the following equation[38]:

Degradation percentage $(\%)=\left[1-\frac{C_{\text {fin }}}{C_{\text {ini }}} \times 100 \%\right]=\left[1-\frac{A_{\text {fin }}}{A_{\text {ini }}} \times 100 \%\right]$

Where, Cini, Cfin, Aini and Afin are the concentration and absorbance of MB dye before and after exposing to visible light irradiation, respectively.

The efficiency of degradation is found to be $79 \%$ after 30 min of irradiation, $82 \%$ after $60 \mathrm{~min}, 86 \%$ for 90 $\mathrm{min}, 86.1 \%$ for $120 \mathrm{~min}$ and $86.3 \%$ after $150 \mathrm{~min}$ as shown in figure (8).

Iron oxide nanoparticles prepared with concentration $0.3 \mathrm{mM}$ of $\mathrm{FeCl} 3$ exhibits high efficiency as photo catalyst without adding $\mathrm{NaOH}$. Degradation of $\mathrm{MB}$ dye obtained by measuring absorbance spectrum as shown in figure (9) the degradation has been measured every $20 \mathrm{~min}$ and the absorbance reached to 0.18 after 120 min of irradiation. The efficiency of degradation is found to be $77 \%$ after 20 min of irradiation, $79 \%$ after $40 \mathrm{~min}, 84 \%$ for $60 \mathrm{~min}, 87.3 \%$ for $80 \mathrm{~min}, 87.8 \%$ after $100 \mathrm{~min}$ and $90 \%$ for $120 \mathrm{~min}$ as shown in figure (10).

\section{Conclusion}

Myrtle leave plant extracts has been approved as both reducing and stabilizing agent for synthesize iron oxide nanoparticles. The presence of nanoparticles was confirmed by $\mathrm{X}$-ray diffraction which showed the average crystalline size of the strongest peaks between $15.59-16.8 \mathrm{~nm}$ in both concentrations $0.1 \mathrm{M}$ and $0.3 \mathrm{mM}$ of $\mathrm{FeCl}_{3}$. FE-SEM images showed different shapes and sizes in different concentrations, such the structure was rod-like shape with size $25-160 \mathrm{~nm}$ in $0.1 \mathrm{M}$ of $\mathrm{FeCl}_{3}$ while, FESEM images showed spherical shape particles with size ranges $(42-67 \mathrm{~nm})$ at $0.3 \mathrm{mM}$ of $\mathrm{FeCl}_{3}$. Optical properties of absorbance spectrum exhibited the maximum values were around $(265-350 \mathrm{~nm})$ and the energy band gaps ( 3 and 3.7) $\mathrm{eV}$ for the two concentrations $\left(0.1 \mathrm{M}\right.$ and $0.3 \mathrm{mM}$ of $\mathrm{FeCl}_{3}$. Synthesized of $\mathrm{Fe}_{2} \mathrm{O}_{3} \mathrm{NPs}$ with two concentrations $\left(0.1 \mathrm{M}\right.$ and $0.3 \mathrm{mM}$ of $\left.\mathrm{FeCl}_{3}\right)$ showed the different behavior in photo catalyst of degradation ability against MBD. Such $0.1 \mathrm{M}$ concentration of $\mathrm{FeCl}_{3}$ was needed to 30 min for degradation with increasing $\mathrm{PH}$ to 10.5 by adding $\mathrm{NaOH}$, until degradation efficiency reached to $86 \%$ after 150 min under irradiation of Halogen light (100 Watt). In case of NPs with $0.3 \mathrm{mM}$ of $\mathrm{FeCl}_{3}$ exhibited more efficiency in degradation of MBD reached to $90 \%$ after 120 min of irradiation without adding $\mathrm{NaOH}$. For this reason, the used of $\mathrm{Fe}_{2} \mathrm{O}_{3} \mathrm{NPs}$ (concentration $0.3 \mathrm{mM}$ of $\mathrm{FeCl}_{3}$ ) with myrtle leaf extract are very effective in breaking down and removing the methylene blue dye polluting the environment. 


\section{References}

1. A. Mubarak, E. Hamzah, and M. R. M. Toff, "Review of physical vapour deposition (PVD) techniques for hard coating," J. Mek., vol. 20, no. 20, pp. 42-51, 2005, doi: 10.13140/RG.2.1.5063.4964.

2. M. Kim, S. Osone, T. Kim, H. Higashi, and T. Seto, "Synthesis of nanoparticles by laser ablation: A review," KONA Powder Part. J., vol. 2017, no. 34, pp. 80-90, 2017, doi: 10.14356/kona.2017009.

3. M. Cesaria et al., Pulsed Laser Ablation: Advances and Applications in Nanoparticles and Nanostructuring Thin Films, no. c. .

4. J. Nayak, C. Devi, and L. Vidyapeeth, "Microwave assisted synthesis: a green chemistry approach," Int. Res. J. Pharm. Appl. Sci., vol. 3, no. 5, pp. 278-285, 2016.

5. S. Horikoshi et al., "Application of variable frequency microwaves in microwave-assisted chemistry: Relevance and suppression of arc discharges on conductive catalysts," Catalysts, vol. 10, no. 7, 2020, doi: $10.3390 /$ catal10070777.

6. E. G. Araújo, R. M. L. Neto, M. F. Pillis, and F. A. Filho, "High-Energy Ball Mill Processing."

7. G. Venugopal and S. Kim, "Nanolithography," 2013.

8. G. R. Suñé, "Electron beam lithography for Nanofabrication," Nanomater. Nanostructures, Nanotechnologie, no. January, pp. 1-20, 2008, doi: 10.1007/s00531-005-0504-1.

9. B. Kwon and J. H. Kim, "Importance of Molds for Nanoimprint Lithography: Hard, Soft, and Hybrid Molds," J. Nanosci., vol. 2016, pp. 1-12, 2016, doi: 10.1155/2016/6571297.

10. D. Vollath, "Plasma synthesis of nanoparticles," KONA Powder Part. J., vol. 25, no. March, pp. 39-55, 2007, doi: 10.14356/kona.2007007.

11. A. Voloshko, "atmospheric pressure To cite this version: Formation de nanoparticules par décharge d ' étincelle à pression atmosphérique par," 2017.

12. N. S. Tabrizi, M. Ullmann, V. A. Vons, U. Lafont, and A. Schmidt-Ott, "Generation of nanoparticles by spark discharge," J. Nanoparticle Res., vol. 11, no. 2, pp. 315-332, 2009, doi: 10.1007/s11051-0089407-y.

13. B. O. Meuller et al., "Review of spark discharge generators for production of nanoparticle aerosols," Aerosol Sci. Technol., vol. 46, no. 11, pp. 1256-1270, 2012, doi: 10.1080/02786826.2012.705448.

14. T. Thunugunta, A. C. Reddy, and D. C. Lakshmana Reddy, "Green synthesis of nanoparticles: Current prospectus," Nanotechnol. Rev., vol. 4, no. 4, pp. 303-323, 2015, doi: 10.1515/ntrev-2015-0023.

15. X. Wang, "Preparation, synthesis and application of Sol-gel method University Tutor: Pr . Olivia GIANI Internship Tutor: Mme. WANG Zhen," no. October, 2020.

16. D. O. V Uche, "Sol-gel technique: A veritable tool for crystal growth," vol. 4, no. 1, pp. 506-510, 2013.

17. "Co-precipitation method of synthesis and characterization of iron oxide nanoparticles," vol. 73, no. February, pp. 87-90, 2014.

18. J. R. Creighton and P. Ho, "Chapter 1 Introduction to Chemical Vapor Deposition (CVD)," Chem. Vap. Depos., no. Cvd, pp. 1-13, 2001. 
19. J. H. Zhou, L. L. Jiang, L. K. Wu, and J. M. Hu, “Photo-assisted electrodeposition of sol-gel films on ptype semiconductors," Electrochem. commun., vol. 61, no. 133, pp. 40-44, 2015, doi: 10.1016/j.elecom.2015.10.002.

20. M. Herlekar, S. Barve, and R. Kumar, "Plant-Mediated Green Synthesis of Iron Nanoparticles," J. Nanoparticles, vol. 2014, pp. 1-9, 2014, doi: 10.1155/2014/140614.

21. A. Ali and S. Ahmed, Green Synthesis of Metal, Metal Oxide Nanoparticles, and Their Various Applications. 2018.

22. J. Singh, T. Dutta, K. H. Kim, M. Rawat, P. Samddar, and P. Kumar, "'Green' synthesis of metals and their oxide nanoparticles: Applications for environmental remediation," J. Nanobiotechnology, vol. 16, no. 1, pp. 1-24, 2018, doi: 10.1186/s12951-018-0408-4.

23. K. N. Thakkar, S. S. Mhatre, and R. Y. Parikh, "Biological synthesis of metallic nanoparticles," Nanomedicine Nanotechnology, Biol. Med., vol. 6, no. 2, pp. 257-262, 2010, doi: 10.1016/j.nano.2009.07.002.

24. G. Benelli, Green synthesis of nanomaterials, vol. 9, no. 9. 2019.

25. S. Saif, A. Tahir, and Y. Chen, "Green Synthesis of Iron Nanoparticles and Their Environmental Applications and Implications," pp. 1-26, 2016, doi: 10.3390/nano6110209.

26. S. Hari, "Biosynthesis of nanoparticles from microorganisms," Res. J. Pharm. Technol., vol. 13, no. 4, pp. 2022-2026, 2020, doi: 10.5958/0974-360X.2020.00364.9.

27. M. A. Mohammad Razi, M. N. A. Mohd Hishammudin, and R. Hamdan, "Factor Affecting Textile Dye Removal Using Adsorbent from Activated Carbon: A Review," MATEC Web Conf., vol. 103, pp. 1-17, 2017, doi: 10.1051/matecconf/201710306015.

28. M. A. Khan, M. I. Khan, and S. Zafar, "Removal of different anionic dyes from aqueous solution by anion exchange membrane," Membr. Water Treat., vol. 8, no. 3, pp. 259-277, 2017, doi: 10.12989/mwt.2017.8.3.259.

29. M. Pourgholi, R. Masoomi Jahandizi, M. Miranzadeh, O. Hassan Beigi, and S. Dehghan, "Removal of Dye and COD from Textile Wastewater Using AOP (UV/O3, UV/H2O2, O3/H2O2 and UV/H2O2/O3)," J. Environ. Heal. Sustain. Dev., no. January 2019, pp. 621-629, 2018, doi: 10.18502/jehsd.v3i4.223.

30. B. Shriram and S. Kanmani, "Ozonation of Textile Dyeing Wastewater - A Review," J. Institue Public Heal. Eng., vol. 2014-15, no. 3, pp. 46-50, 2014.

31. K. Singh and S. Arora, "Removal of synthetic textile dyes from wastewaters: A critical review on present treatment technologies," Crit. Rev. Environ. Sci. Technol., vol. 41, no. 9, pp. 807-878, 2011, doi: $10.1080 / 10643380903218376$.

32. D. Bhatia, N. R. Sharma, J. Singh, and R. S. Kanwar, "Biological methods for textile dye removal from wastewater: A review," Crit. Rev. Environ. Sci. Technol., vol. 47, no. 19, pp. 1836-1876, 2017, doi: 10.1080/10643389.2017.1393263.

33. M. S. H. Bhuiyan et al., "Green synthesis of iron oxide nanoparticle using Carica papaya leaf extract: application for photocatalytic degradation of remazol yellow RR dye and antibacterial activity," Heliyon, vol. 6, no. 8, p. e04603, 2020, doi: 10.1016/j.heliyon.2020.e04603. 
34. O. D. K. Szostak and M. K. M. Banach, "Synthesis of Fe 304 / ZnO nanoparticles and their application for the photodegradation of anionic and cationic dyes," Int. J. Environ. Sci. Technol., vol. 18, no. 3, pp. 561-574, 2021, doi: 10.1007/s13762-020-02852-4.

35. V. K. Nathan, P. Ammini, and J. Vijayan, "Photocatalytic degradation of synthetic dyes using iron (III) oxide nanoparticles (Fe 203 -Nps) synthesised using Rhizophora mucronata Lam," IET Nanobiotechnology, vol. 13, no. 2, pp. 120-123, 2019, doi: 10.1049/iet-nbt.2018.5230.

36. H. Gupta, R. Kumar, H. S. Park, and B. H. Jeon, "Photocatalytic efficiency of iron oxide nanoparticles for the degradation of priority pollutant anthracene," Geosystem Eng., vol. 20, no. 1, pp. 21-27, 2017, doi: 10.1080/12269328.2016.1218302.

37. M. A. Abid and D. A. Kadhim, "Novel comparison of iron oxide nanoparticle preparation by mixing iron chloride with henna leaf extract with and without applied pulsed laser ablation for methylene blue degradation," J. Environ. Chem. Eng., vol. 8, no. 5, p. 104138, 2020, doi: 10.1016/j.jece.2020.104138.

38. W. J. Aziz, M. A. Abid, D. A. Kadhim, and M. K. Mejbel, "Synthesis of iron oxide ( $\beta$-fe2o3) nanoparticles from Iraqi grapes extract and its biomedical application," IOP Conf. Ser. Mater. Sci. Eng., vol. 881, no. 1, 2020, doi: 10.1088/1757-899X/881/1/012099.

\section{Figures}

(a)

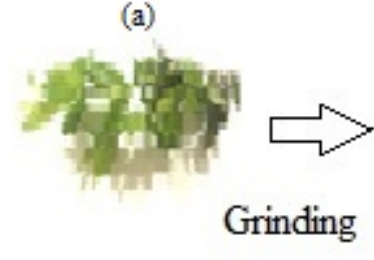

(b)

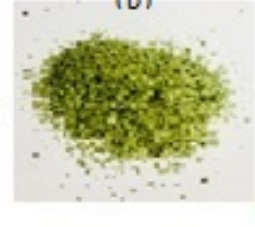

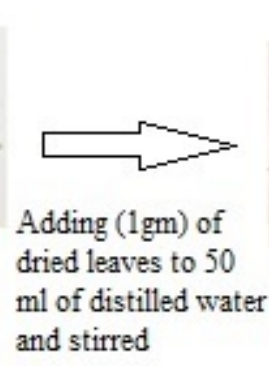

(e)

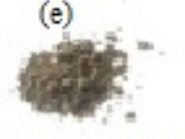

Nanoparticles powder (c)

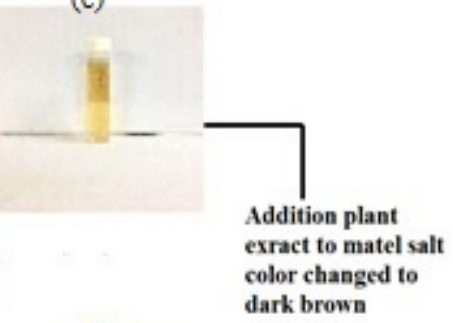

(d)

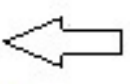

I

\section{Figure 1}

Diagram of Fe203 NPs formation with plant (a): myrtle leaves (b): myrtle leave after grinding, (c): plant extract by adding $1 \mathrm{gm}$ to distilled water (d): formation of nanoparticles by adding plant extract to metal salt, (e): NPs powder after drying in oven at $300 \mathrm{oC}$. 


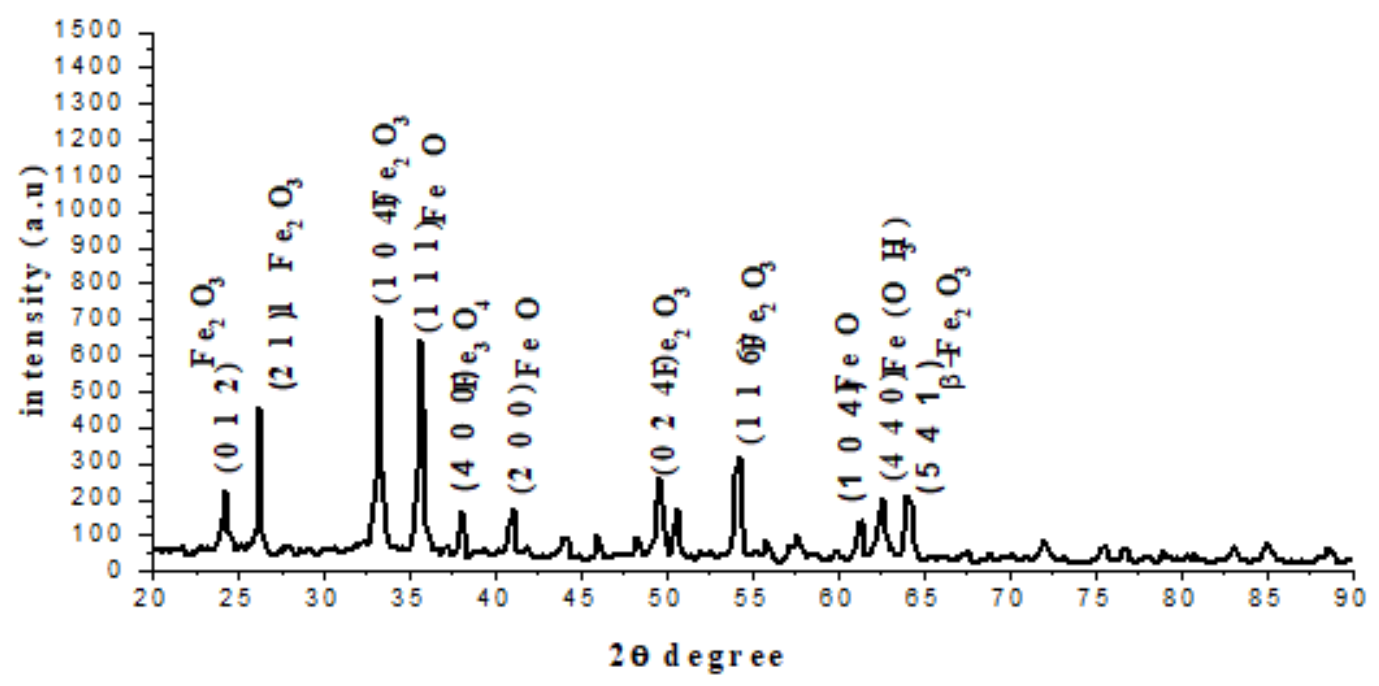

(A)

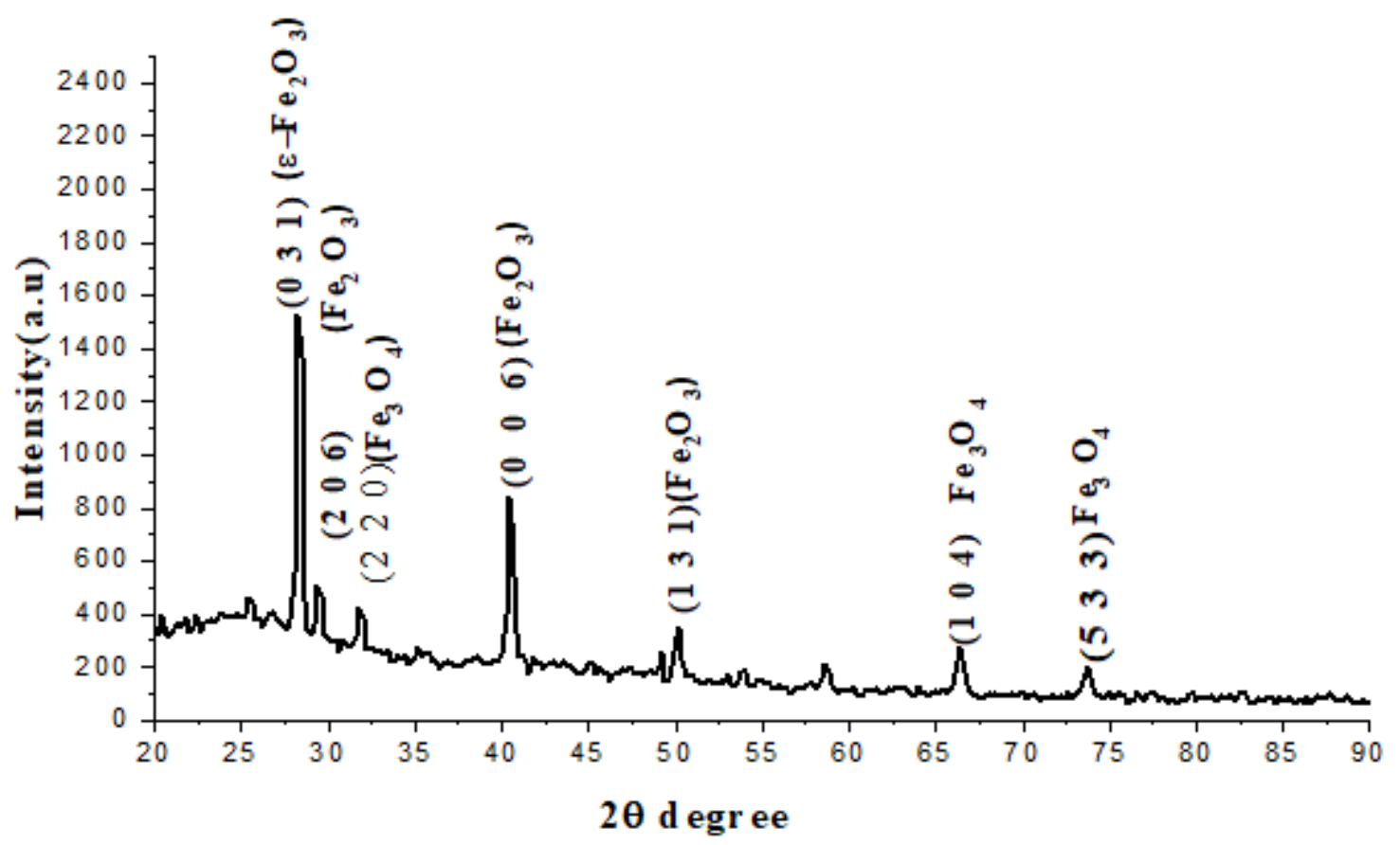

(B)

Figure 2

XRD pattern of iron oxide synthesize using myrtle leaves plant extract $(A)$ : with concentration $0.1 \mathrm{M}$ of $\mathrm{FeCl} 3$, (B): with concentration of $0.3 \mathrm{mM}$. 

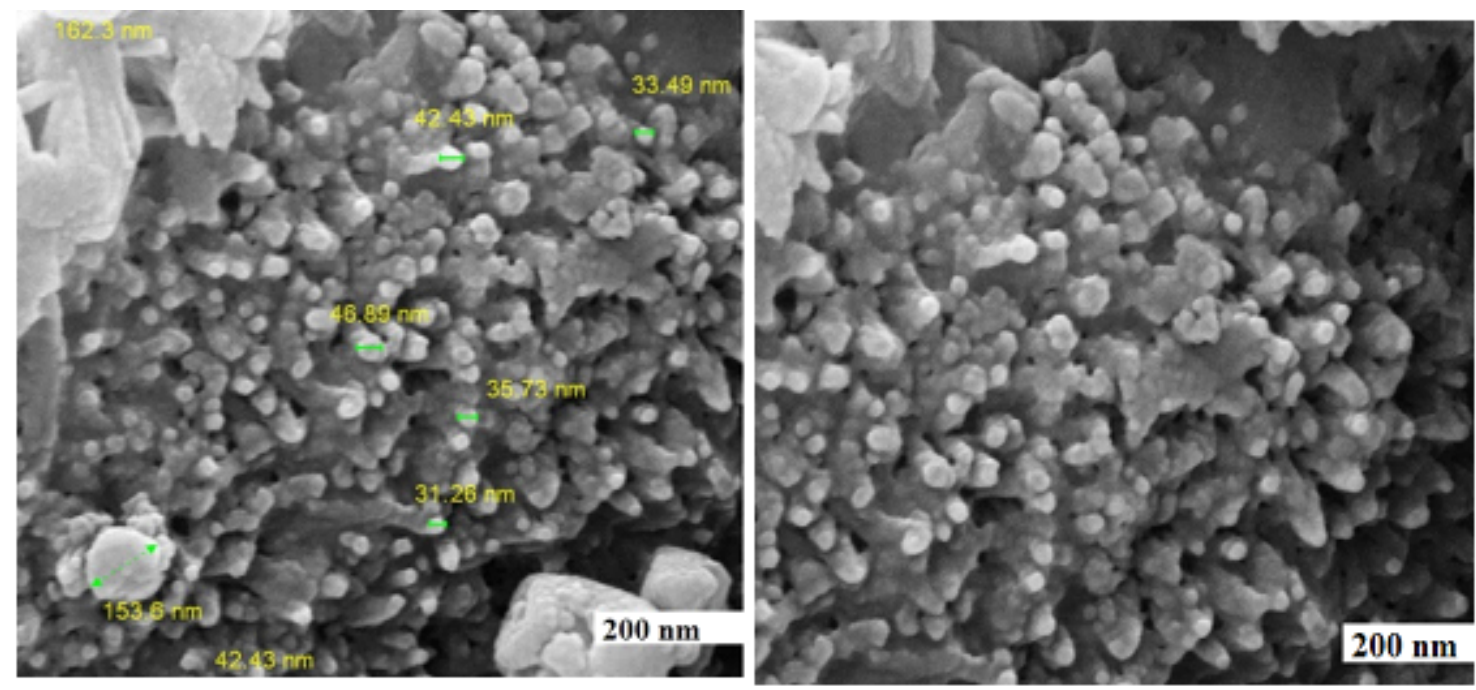

(A)

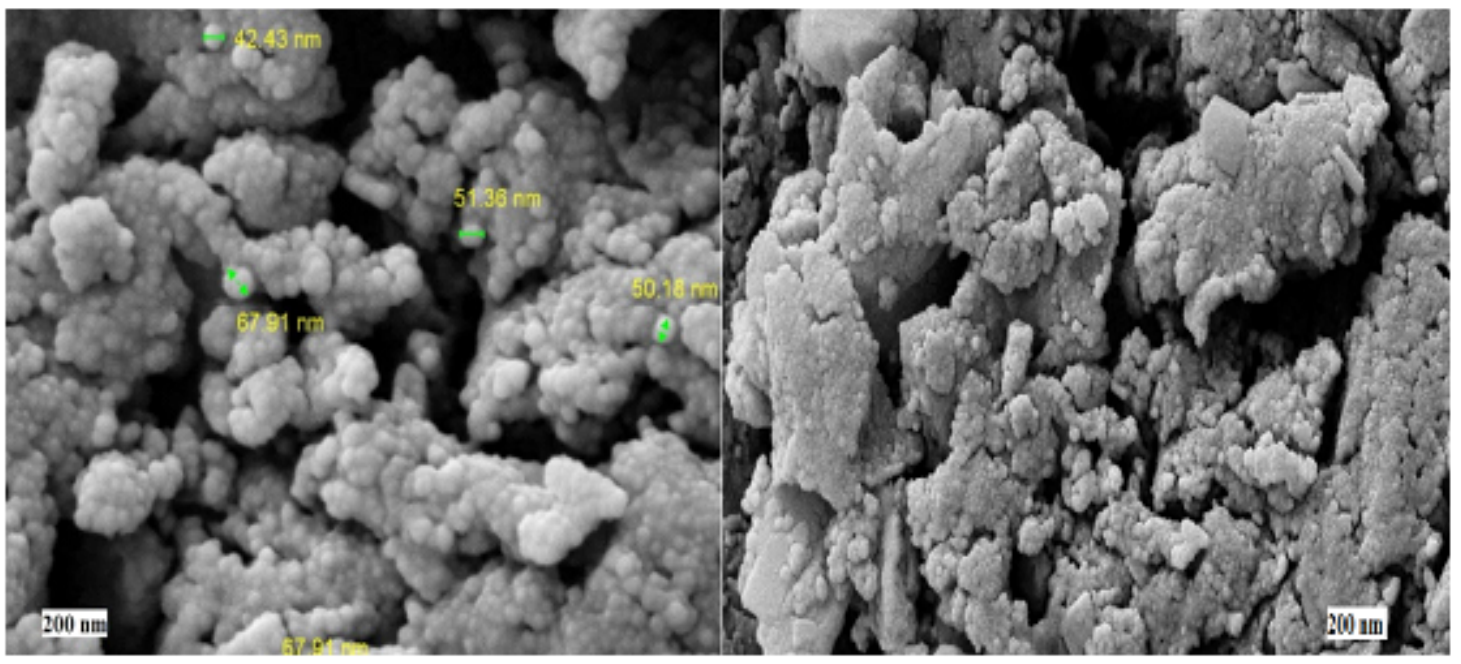

(B)

\section{Figure 3}

FE-SEM of iron oxide mixed with myrtle leaves extract, (A): $0.1 \mathrm{M}$ concentration of $\mathrm{FeCl} 3$, (B): $0.3 \mathrm{mM}$ concentration of $\mathrm{FeCl} 3$. 


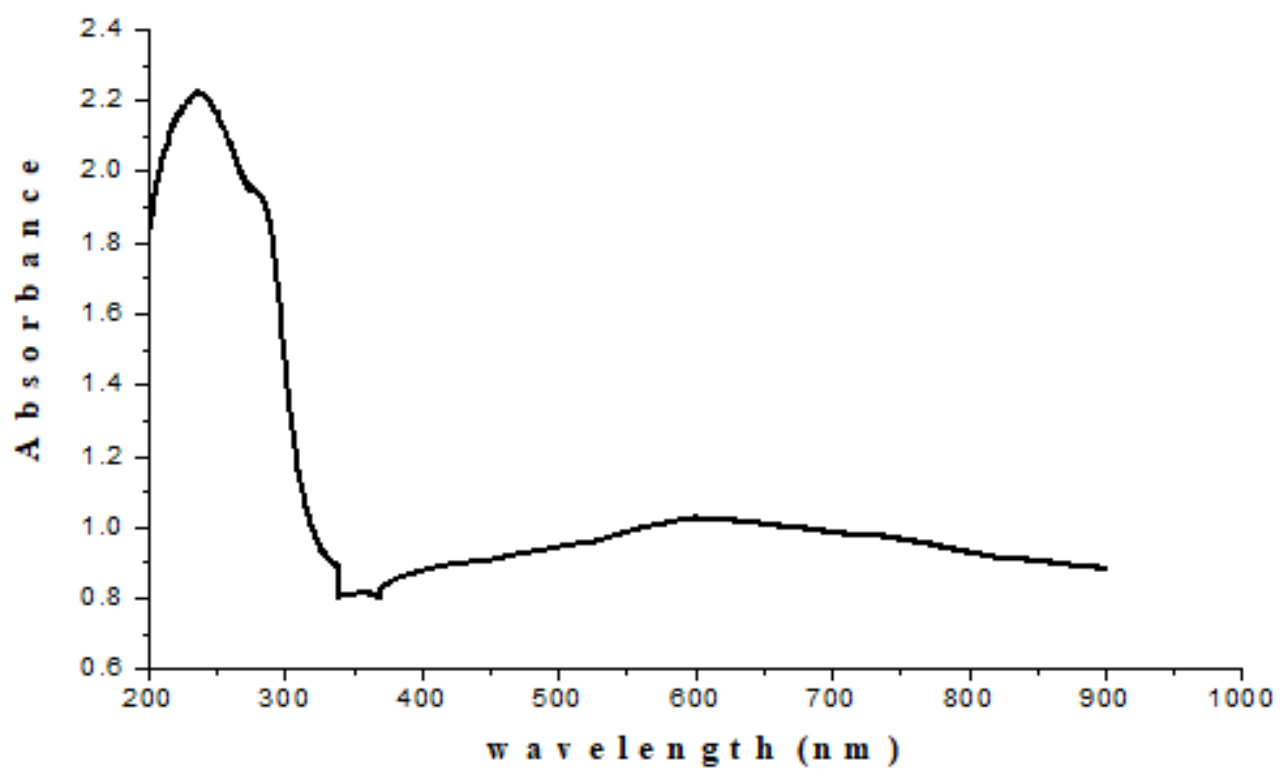

(A)

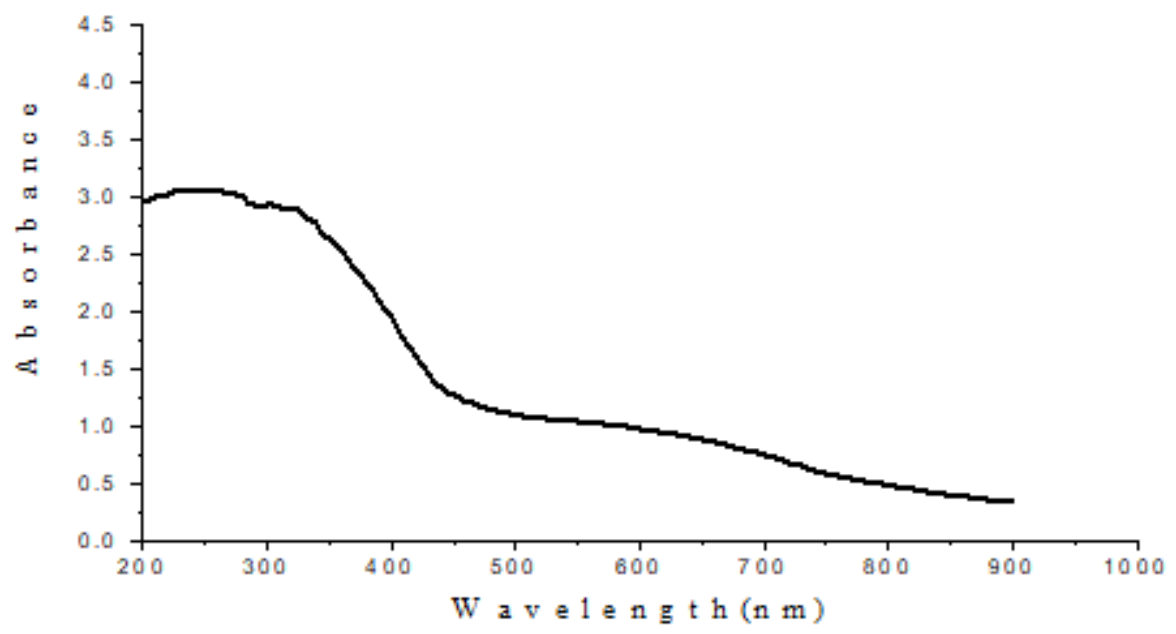

(B)

Figure 4

Absorbance spectrum of synthesized iron oxide NPs with plant extracts (A): $0.1 \mathrm{M}$ concentration and (B): $0.3 \mathrm{mM}$ concentration of $\mathrm{FeCl}$. 


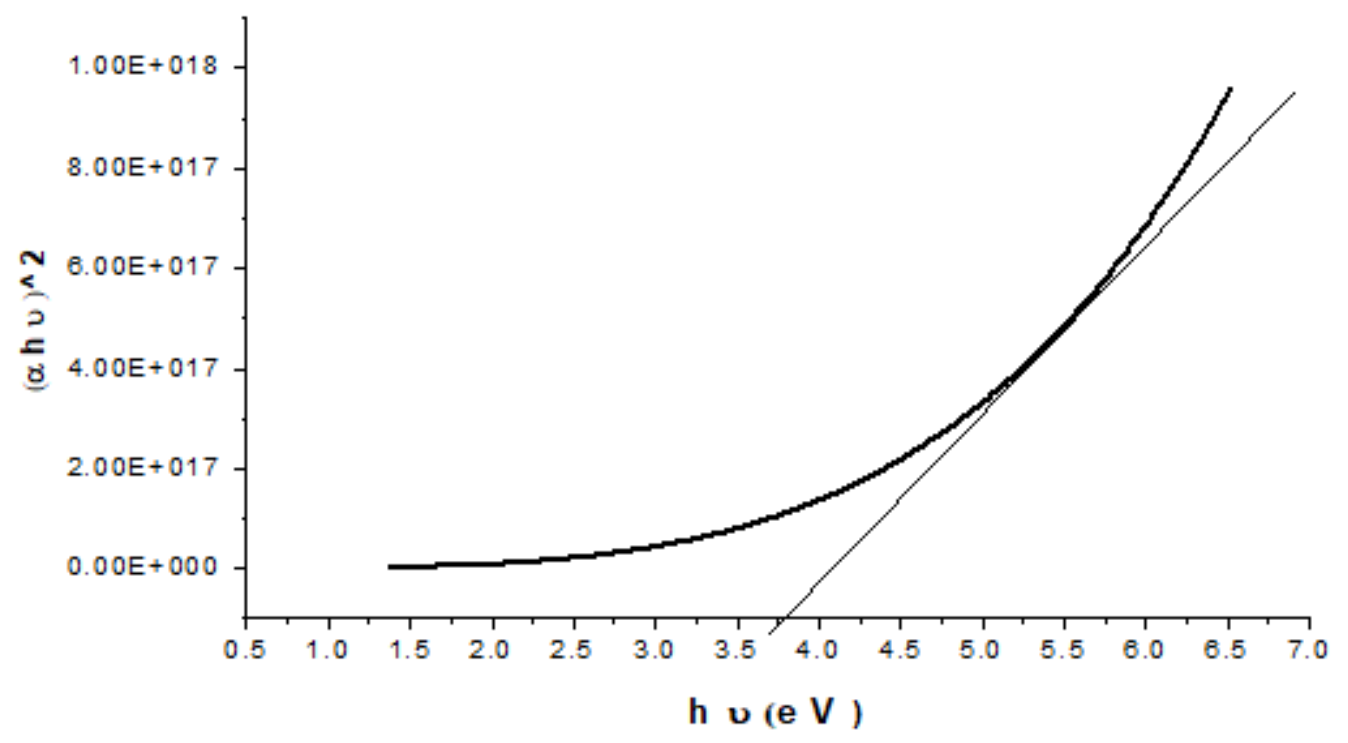

(A)

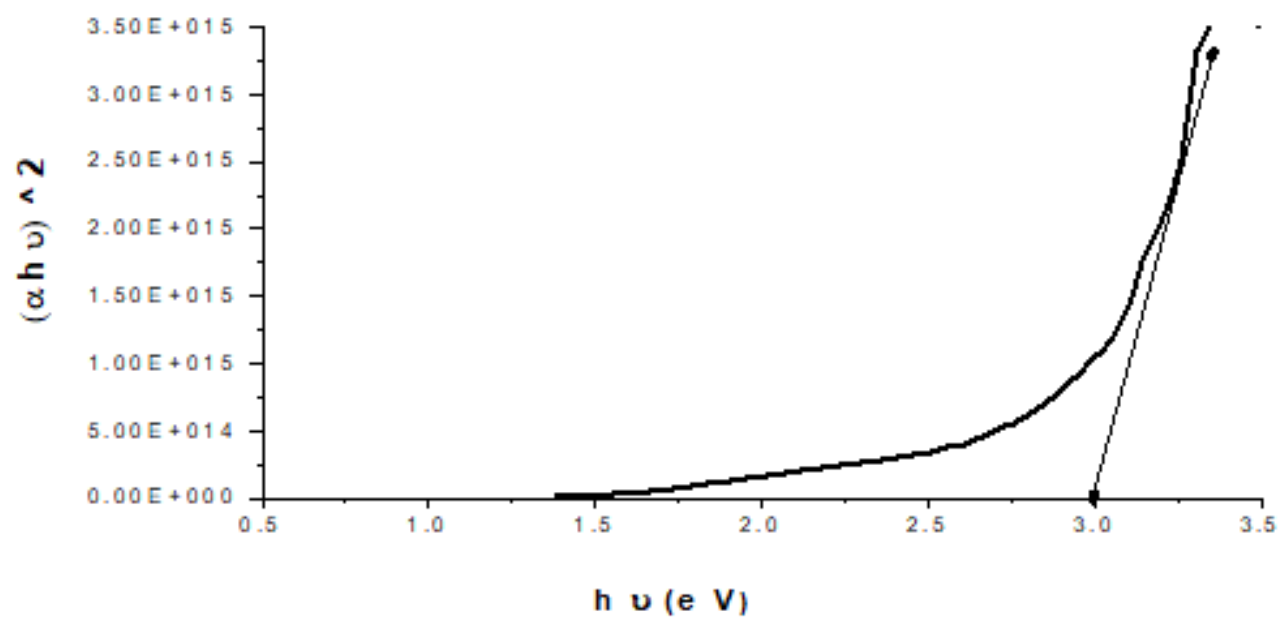

(B)

\section{Figure 5}

Energy band gap of prepared nanoparticles with plant extract (A): $0.1 \mathrm{M}$ concentration and (B): $0.3 \mathrm{mM}$ concentration of $\mathrm{FeCl} 3$. 


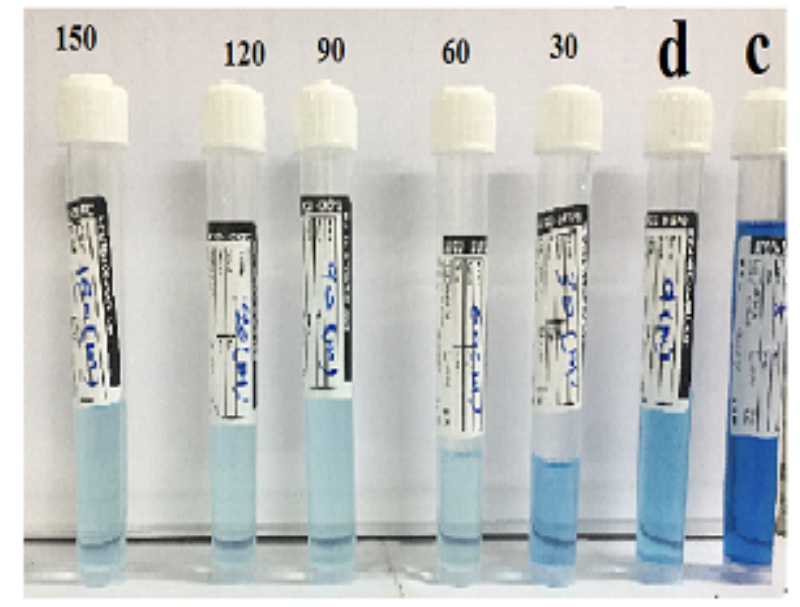

(A)

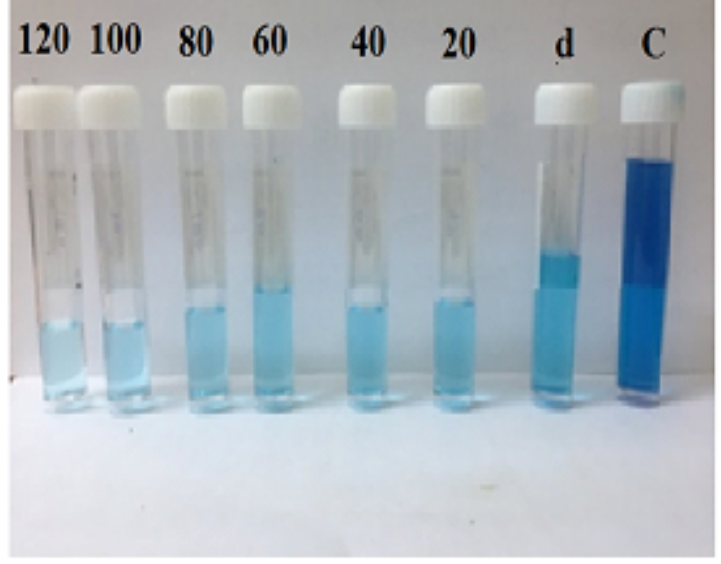

(B)

\section{Figure 6}

Degradation of MBD in the dark and irradiation, (A): degradation each 30 min by Fe2O3 NPs prepared with $0.1 \mathrm{M}$ of $\mathrm{FeCl} 3,(\mathrm{~B})$ : degradation each 20 min by Fe2O3 NPs prepared with $0.3 \mathrm{mM}$ of $\mathrm{FeCl} 3$.

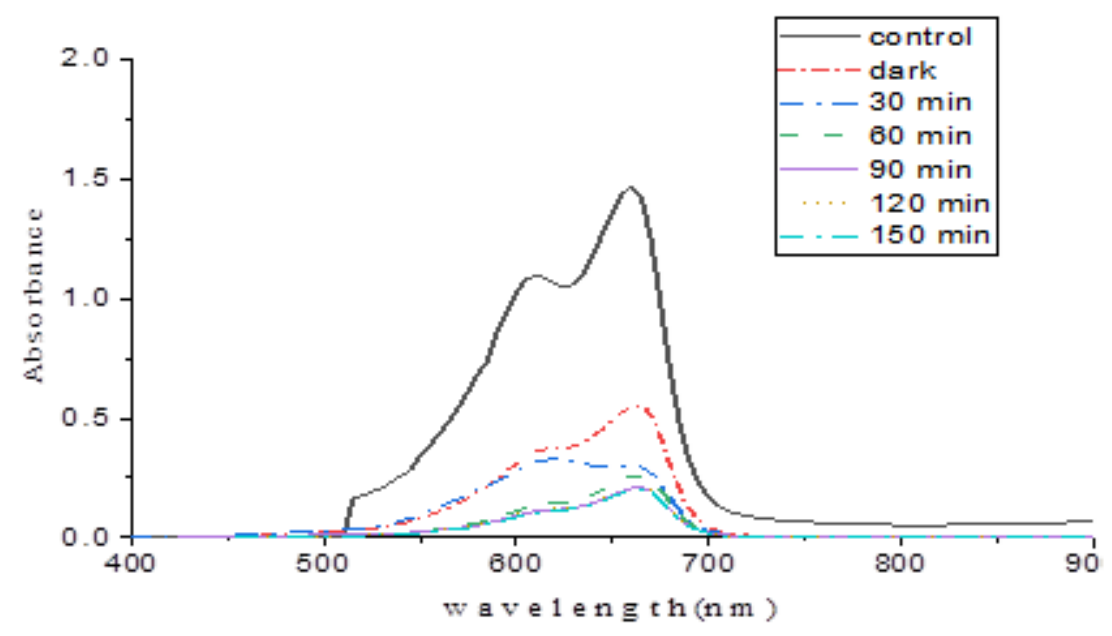

Figure 7

UV-Vis spectrophotometer of degradation of MBD under irradiation with iron oxide nanoparticles of ( 0.1 $\mathrm{M}$ of $\mathrm{FeCl} 3$ ) as photo catalyst. 


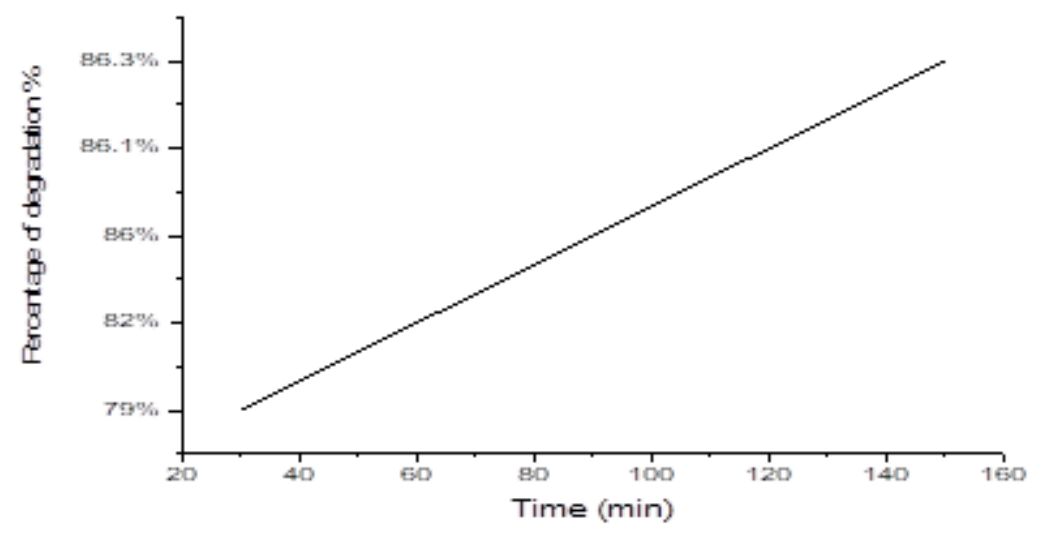

Figure 8

The percentage degradation of MBD at $1 \mathrm{mg} / \mathrm{L}$ by Fe2O3 NPs prepared using myrtle leave extract with different time of irradiation

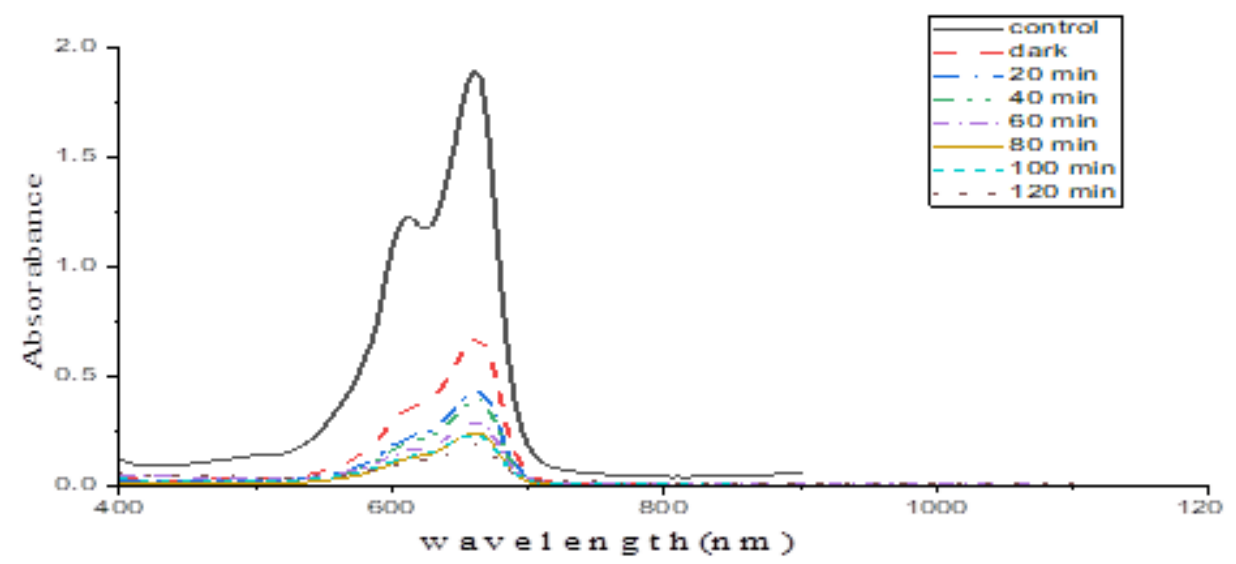

\section{Figure 9}

UV-Vis spectrophotometer of degradation of MBD under irradiation with iron oxide nanoparticles of $(0.3$ $\mathrm{mM}$ of $\mathrm{FeCl} 3$ ) as photo catalyst.

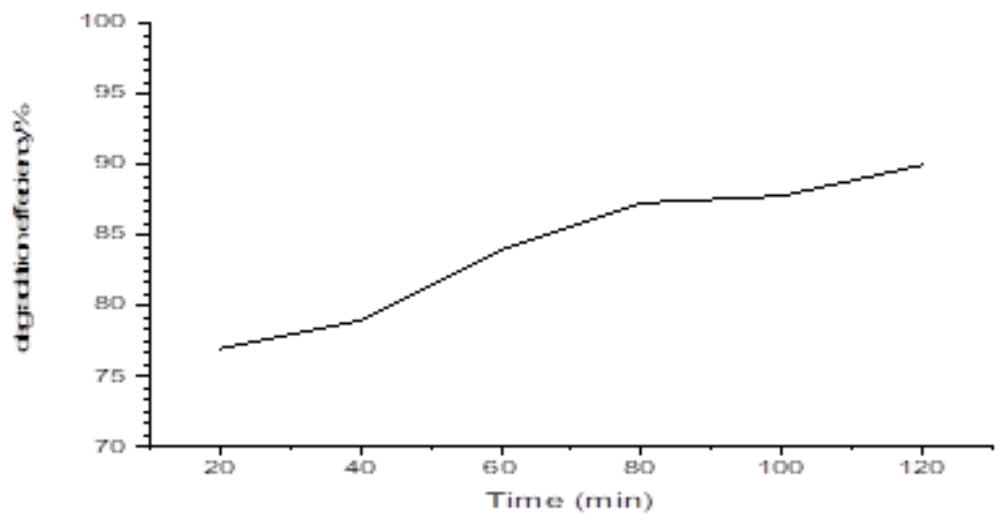


Figure 10

The percentage degradation of MBD at $1 \mathrm{mg} / \mathrm{L}$ by Fe2O3 NPs prepared using myrtle leave extract with concentration $(0.3 \mathrm{mM}$ of $\mathrm{FeCl} 3)$ with different time of irradiation.

\section{Supplementary Files}

This is a list of supplementary files associated with this preprint. Click to download.

- floatimage1.png 